\title{
A REORIENTAÇÃO MARXIANA DO MÉTODO
}

\author{
Itsvan Mészáros ${ }^{\mathrm{i}}$
}

\begin{abstract}
RESUMO:
Este artigo é parte das reflexões presentes no livro "Estrutura Social e Formas de consciência: a determinação social do método" publicado pela Editora Boitempo Editorial no ano de 2009. Debate a dimensão do método científico e seus desdobramentos sociais, desenvolvendo crítica radical à concepção da ciência expressa pressupostos teóricos desvinculada dos interesses de classe e grupos sociais. A produção da atividade científica é determinada pelos interesses do capital e a superação dessa condição implica na superação do próprio capital. Como bem afirma Marx a problematização da sociedade capitalista implica na recuperação da sua historicidade e, consequentemente, a necessidade de sua superação.

Palavras-chave: Marxismo; Ciência; Ideologia; Luta de classes; Socialismo
\end{abstract}

\section{MARXIAN REORIENTATION OF METHOD}

\begin{abstract}
:
This article is part of the reflexions present in the book "Social Structure and forms of consciousness: the social determination of the method" published by Editorial Boitempo in 2009. Discussion of the size of the scientific method, and its social consequences, developing a radical critique of science to the design expresses theoretical untied class interests and social groups. The production of scientific activity is determined by the interests of capital and the overcoming of this condition implies the overcoming of capital itself. Well as Marx said the questioning of capitalist society implies the restoration of its historicity, and therefore the need to overcome them.
\end{abstract}

Keywords: Marxism, Science, Ideology, Class struggle, Socialism

O bastante conhecido "Prefácio" de Marx à sua Contribuição à crítica da economia política de 1859 é de absoluta relevância para nosso presente contexto. Esse texto apresenta duas proposições igualmente importantes. Primeiro, que a ordem sociometabólica do capital há muito estabelecida é a última forma de reprodução social antagônica na história humana; segundo, que as condições materiais para superar o antagonismo estrutural da ordem socioeconômica agora dominante são elas mesmas criadas no interior da estrutura da sociedade burguesa dada. Estas são suas palavras:

As relações de produção burguesas são a última forma contraditória do processo de produção social, contraditória não no sentido de uma contradição individual, mas de uma contradição que nasce das condições de existência social dos indivíduos. No entanto, as forças produtivas que se desenvolvem no seio da sociedade burguesa criam ao mesmo tempo as condições materiais para resolver essa contradição. ${ }^{\text {ii }}$

A primeira proposição é importante porque o antagonismo entre capital/trabalho é um antagonismo de classes fundamental, que subjuga a esmagadora maioria da sociedade 
à dominação estrutural hierárquica do capital. É uma relação não reformável de dominação e subordinação a qual poderia não ser reproduzida de modo sustentável em uma sociedade futura por meio da inversão dos papéis entre a vasta maioria dominada e a pequena minoria dominante. Pois esta seria muito incapaz de reproduzir sozinha as condições primárias de existência até para ela mesma, sem mencionar para toda a sociedade.

No que se refere à relevância vital da segunda proposição, é necessário lembrar que sem um nível avançado de atividade produtiva, que seja plenamente adequado para satisfazer as necessidades genuínas da totalidade dos indivíduos sociais - em contraste com a amplamente discriminatória distribuição do produto social em favor de uma minúscula minoria no passado -, os conflitos e antagonismos se sucederiam. ${ }^{\text {iii }}$ É por esse motivo que Marx insiste, na mesma página do citado "Prefácio" de sua Contribuição à crítica da economia política, que:

Uma organização social nunca desaparece antes que se desenvolvam todas as forças produtivas que ela é capaz de conter; nunca relações de produção novas e superiores se lhe substituem antes que as condições materiais de existência destas relações se produzam no próprio seio da velha sociedade. É por isso que a humanidade só levanta os problemas que é capaz de resolver e assim, numa observação atenta, descobrir-se-á que o próprio problema só surgiu quando as condições materiais para o resolver já existiam ou estavam, pelo menos, em vias de aparecer. ${ }^{\text {iv }}$

Dois comentários são necessários a esta altura, não apenas para evitar desentendimentos, mas também para combater certa hostilidade superficial. O primeiro é que Marx fala apenas sobre a criação das condições materiais necessárias dentro da estrutura da antiga sociedade, repetindo a mesma expressão diversas vezes em uma curta passagem. Ele está bastante consciente da necessidade de se desenvolver de maneira apropriada as condições políticas e culturais/teóricas - assim como as educacionais existentes - que apresentam um grande desafio para futuro. É por isso que Marx frisa que "o próprio educador tem de ser educado", em franco contraste com o socialismo utópico, a exemplo da posição de Robert Owen - segundo ele, é preciso "dividir a sociedade em duas partes [os educadores e os educados], a primeira das quais está colocada acima da sociedade". E Marx também se refere a uma tarefa histórica inevitável para a "criação em massa dessa consciência comunista", que significa "a consciência da necessidade de uma revolução radical"," Em outras palavras, o bem-sucedido cumprimento da tarefa histórica exige o preenchimento de um empreendimento revolucionário político, teórico e educacional ao qual o próprio Marx dedica sua vida inteira, precisamente porque essas dimensões do desafio histórico em questão não podem ser resolvidas pelos processos materiais espontâneos da antiga sociedade.

$\mathrm{O}$ segundo comentário que deve ser adicionado aqui refere-se à gravidade e à urgência dos problemas que temos de enfrentar sob as presentes condições históricas da ordem antagônica do capital. Pois, nesse aspecto, as décadas de desenvolvimento pósSegunda Guerra tornaram a situação incomparavelmente mais grave do que fora durante a vida de Marx. Sem dúvida, ele já havia sublinhado em 1845 que, devido aos antagonismos alienantes do modo de controle de reprodução social do capital,

No desenvolvimento das forças produtivas advém uma fase em que surgem forças produtivas e meios de intercâmbio que, no marco das relações existentes, causam somente malefícios e não são mais forças de produção, mas forças de destruição. ${ }^{\text {iii }}$

E antecipando o sentido do célebre aviso de Rosa Luxemburgo sobre "socialismo ou barbárie", Marx também insistiu, na mesma obra, que: 
Chegou-se a tal ponto, portanto, que os indivíduos devem apropriar-se da totalidade existente de forças produtivas, não apenas para chegar à autoatividade, mas simplesmente para assegurar a sua existência. ${ }^{\text {vii }}$

Entretanto, o que na década de 1840 era uma remota possibilidade até mesmo em termos tecnológicos militares, atualmente tornou-se uma inegável e assustadora realidade. Pois, desde o tempo em que essas linhas citadas foram escritas por Marx, a humanidade teve de confrontar não apenas as desumanidades de duas guerras mundiais devastadoras, junto com uma multiplicidade de conflagrações militares menos globais, mas não menos destrutivas - incluindo a Guerra do Vietnã e a atual intervenção genocida promovida pelo dominante poder imperialista no Oriente Médio -, como também a possibilidade de uma aniquilação potencial de toda a humanidade e, ao mesmo tempo, a destruição de toda a vida sobre a Terra, por meio de armas de destruição em massa nucleares, químicas e biológicas prontas para serem ativadas com a maior facilidade. E como se isso não fosse o bastante, as práticas produtivas ubiquamente impostas da produção destrutiva do capital já estão ativamente engajadas em infligir danos irreversíveis sobre a própria natureza, minando com isso as condições elementares de existência da humanidade. Assim, por um lado, enquanto no passado nunca se deu ao potencial produtivo um uso positivo, por outro, a realidade destrutiva dos desenvolvimentos em andamento - tanto no plano militar quanto no de reprodução social não apenas se equipara como também supera as forças produtivas da humanidade a ponto de uma destruição potencialmente total, sob o controle das personificações mais que ávidas do capital. Pois destruir é muito mais fácil que construir. É isso que inevitavelmente qualifica a sentença de Marx citada, segundo a qual "a humanidade só levanta os problemas que é capaz de resolver".

Como mencionado nos parágrafos finais da seção 7.5, sob as presentes condições de aprofundamento da crise estrutural do sistema do capital, a elaboração de um modo qualitativamente diverso e não antagônico para mediar o metabolismo social é a condição vital de sucesso para o futuro. Consequentemente, a necessária preocupação com as questões do método apropriado para manejar os severos problemas e dificuldades de nossa época de transição histórica está intimamente relacionada a este tópico. A importância dessa exigência mediadora qualitativamente nova não pode ser exagerada. Pois, se aqui se provar impossível a elaboração no futuro próximo de um modo não antagônico de mediação da relação entre humanidade e natureza, assim como entre os próprios indivíduos, isso poderia fazer da viabilidade mesma de instituir uma ordem reprodutiva socialista genuína algo muito desanimador.

O ponto de partida necessário nesse aspecto, para a reorientação do método herdado do passado, é submeter a uma crítica radical a modalidade estabelecida de mediação de reprodução social sob o domínio do capital. Esse ponto pode ser resumido a partir da diferença fundamental entre mediações de primeira e de segunda ordem. Estas, como as conhecemos, são mediações irremediavelmente antagônicas, constituindo um sistema de controle sociometabólico que precisa ser superado em sua totalidade, como um "sistema perversamente orgânico", e substituído por sua alternativa hegemônica, constituída e consolidada, novamente, como um sistema orgânico historicamente viável e totalmente cooperativo. A teoria da alienaçãa $o^{i x}$ de Marx, na qualidade de arcabouço explanatório das mediações de segunda ordem antagônicas do capital, está profundamente concentrada em tais problemas. Seus primeiros diagnósticos e soluções estão articulados em seu sistema in statu nascendi, por ele escritos em Paris e publicados postumamente sob o título Manuscritos econômico-filosóficos de 1844. 
O contraste entre as mediações primárias e as antagônicas mediações de segunda ordem é absolutamente impressionante. As mediações necessárias para todas as formas viáveis de reprodução social são:

- a regulação necessária, mais ou menos espontânea, da atividade biológica reprodutiva e o tamanho da população sustentável, em conjunção com os recursos disponíveis;

- a regulação do processo de trabalho por meio do qual o necessário intercâmbio da comunidade com a natureza possa produzir os bens necessários para a satisfação humana, como também as ferramentas de trabalho, empreendimentos produtivos e conhecimento apropriados pelos quais o próprio processo reprodutivo possa ser mantido e aprimorado;

- o estabelecimento de relações de troca adequadas sob as quais as necessidades historicamente cambiantes dos seres humanos possam ser interligadas com o propósito de otimizar os recursos naturais e produtivos disponíveis - incluindo os culturalmente produtivos;

- a organização, a coordenação e o controle da multiplicidade de atividades por meio das quais as exigências materiais e culturais do processo de reprodução sociometabólico bem-sucedido de comunidades humanas progressivamente mais complexas possam ser asseguradas e protegidas;

- a alocação racional dos recursos materiais e humanos disponíveis, lutando contra a tirania da escassez por meio da utilização econômica (no sentido de economizar) dos modos e meios de reprodução da sociedade dada, na medida do viável sobre a base de um nível de produtividade alcançável e dentro dos limites das estruturas socioeconômicas estabelecidas;

- e a promulgação e a administração de regras e regulamentos da sociedade dada como um todo, em conjunção com outras funções e determinações primárias mediadoras.

Como podemos ver, nenhum desses imperativos mediadores primários em e por si mesmos implica o estabelecimento de hierarquias estruturais de dominação e subordinação como a estrutura necessária da reprodução sociometabólica. Em franco contraste, as mediações de segunda ordem do sistema do capital não poderiam ser mais distintas em seu caráter. Elas podem ser resumidas da seguinte forma:

- a família nuclear, articulada como o "microcosmo" da sociedade, o qual, além de seu papel na reprodução da espécie, participa em todas as relações reprodutivas do "macrocosmo" social, incluindo a mediação necessária das leis do Estado para todos os indivíduos e, assim, diretamente necessária também para a reprodução do Estado;

- os meios de produção alienados e suas "personificações" por meio das quais o capital adquire "vontade férrea" e consciência rígida, estritamente demandado a impor sobre todos a conformidade com relação às exigências objetivas desumanizantes da ordem sociometabólica dada;

- o dinheiro assumindo uma multiplicidade de formas mistificantes e progressivamente mais dominantes no curso do desenvolvimento histórico, chegando ao domínio total do sistema monetário internacional dos dias de hoje; - objetivos de produção fetichistas, submetendo de uma forma ou de outra a satisfação de necessidades humanas (e a provisão correspondente de valores de uso) aos imperativos cegos da expansão e acumulação do capital; 
- trabalho estruturalmente divorciado da possibilidade de controle, seja nas sociedades capitalistas, nas quais deve funcionar como trabalho asssalariado coagido e explorado pela compulsão econômica, seja sob o controle póscapitalista do capital sobre a força de trabalho politicamente dominada;

- variedades de formação de Estado do capital em seus terrenos globais, nos quais podem confrontar-se uns contra os outros (por vezes com os mais violentos meios, deixando a humanidade à beira da autodestruição), como Estados nacionais orientados a si mesmos;

- e o descontrolado mercado mundial em cuja estrutura os participantes, protegidos por seus respectivos Estados nacionais por meio das relações de poder dominantes, devem se acomodar às precárias condições de coexistência econômica enquanto se empenham em obter a mais alta vantagem praticável para si ao ludibriar suas contrapartes concorrentes, aqui lançando inevitavelmente as sementes de mais conflitos destrutivos.

Em relação à maneira em que todos esses componentes do modo de controle sociometabólico estabelecido estão interligados podemos apenas nos referir a um círculo vicioso. Pois as mediações de segunda ordem particulares se sustentam reciprocamente, tornando impossível impedir a força alienante e paralisante de qualquer um deles quando tomados isoladamente, enquanto o imenso poder de autorregeneração e de imposição do sistema como um todo é deixado intacto. Com base em dolorosa evidência histórica, a verdade desconcertante é que o sistema do capital tem sucesso em impor-se - por meio de interconexões estruturais de suas partes constituintes - sobre esforços emancipatórios parciais dirigidos a alvos específicos e limitados. Por conseguinte, o que deve ser confrontado e superado pelos adversários da ordem de reprodução sociometabólica estabelecida e incorrigivelmente discriminatória é não apenas a força definitivamente autossustentadora da extração de mais-valia do trabalho do capital, mas também o poder negativo devastador - a inércia aparentemente proibitiva - de suas conexões circulares ${ }^{\mathrm{x}}$.

A concepção que vislumbra a superação das mediações de segunda ordem antagônicas do capital é inseparável da reavaliação radical do contraste metodologicamente seminal entre o ponto de vista da filosofia, herdado da típica caracterização burguesa da ordem social, e o qualitativamente diverso ponto de vista oferecido pelo próprio Marx. Do modo como formulara na décima de suas "Teses sobre Feuerbach", Marx insistiu que "o ponto de vista do velho materialismo é o da sociedade civil; o ponto de vista do novo é o da sociedade humana, ou o da humanidade social". Ao mesmo tempo, na orientação marxiana do método, a relevância desse necessário ponto de vista que parte da sociedade civil não pode confinar-se ao antigo materialismo, contrastado naquela "Tese sobre Feuerbach" com a defesa marxiana do materialismo. Pois, de modo característico, as filosofias idealistas especulativas, incluindo a de Hegel - com suas postuladas "individualidades agregativas", supostamente fazendo valer enquanto indivíduos egoístas os interesses conflitivos estritamente individualistas de cada indivíduo particular contra todos os outros - são caracterizadas pelas mesmas limitações de ponto de vista. Marx tornou isso muito claro em seu "Prefácio" de 1859 à Contribuição à crítica da economia política, ao acentuar que:

Nas minhas pesquisas cheguei à conclusão de que as relações jurídicas - assim como as formas de Estado - não podem ser compreendidas por si mesmas, nem pela dita evolução geral do espírito humano, inserindo-se pelo contrário nas condições materiais de existência de que Hegel, à semelhança dos ingleses e franceses do século XVIII, 
compreende o conjunto pela designação de "sociedade civil"; por seu lado, a anatomia da sociedade civil deve ser procurada na economia política. ${ }^{\mathrm{xi}}$

A razão pela qual a adoção do "ponto de vista da sociedade civil" como o princípio orientador geral da filosofia teve de ser submetida a uma crítica radical foi porque, ao reduzir de maneira conveniente as contradições sociais antagônicas da ordem social estabelecida às vicissitudes estritamente pessoais de indivíduos egoístas, e a partir disso hipostasiar tais contradições como ontologicamente insuperáveis, a ordem hierárquica social efetivamente existente, em princípio, permaneceu além da crítica. E pode prosseguir exatamente como antes com suas atividades reprodutivas no interior da estrutura de suas destrutivas e definitivamente autodestrutivas - mediações antagônicas de segunda ordem. Pois, se os problemas reais do antagonismo social são transfigurados individualisticamente e abstraídos de modo arbitrário do único substrato no qual podem ser abordados de maneira apropriada, a saber, na dita "sociedade civil" mesma, na qual as "condições materiais de existência" as produzem e reproduzem constantemente, naquele caso a posição metodológica adotada pode cumprir de modo bem-sucedido sua função ideológica de racionalizar o existente em um modo plenamente conciliador. É por esse motivo que Marx insiste, na citação anterior, que a sociedade burguesa era "contraditória não no sentido de uma contradição individual, mas de uma contradição que nasce das condições de existência social dos indivíduos", adicionando ao mesmo tempo a condição crítica crucial de que "as forças produtivas que se desenvolvem no seio da sociedade burguesa criam ao mesmo tempo as condições materiais para resolver esta contradição"xii. Este foi precisamente o tipo de diagnóstico, tanto das contradições realmente existentes quanto de sua potencial resolução, que precisava ser evitado por todos aqueles que adotaram em suas conceituações do mundo o eternizante "ponto de vista da sociedade civil".

Ademais, esse tipo de tratamento da "sociedade civil", adotado já pelos grandes representantes intelectuais da burguesia em ascensão, possuía o benefício adicional para eles de ajudar a criar as condições especulativas para a idealização do próprio Estado capitalista ao separar a dimensão política abrangente dos problemas de seu solo material por meio da abstração imaginária do estado da realidade material da "sociedade civil". Essa abordagem característica de separação estrutural foi duplamente conveniente. Pois o que podia, ao menos em princípio, trazer resultados no mundo real, a confrontação necessária dos antagonismos materiais e políticos intimamente associados - na medida em que progrediram no âmbito reprodutivo da "sociedade civil" -, foi categoricamente excluído de qualquer consideração em vista da falsa conceituação da sociedade civil como sendo o terreno da individualidade agregativa estritamente egoísta. E, pelo mesmo motivo, no idealizado domínio separado do Estado, no qual os antagonismos materiais da sociedade não poderiam sequer ser identificados de maneira apropriada, muito menos adequadamente superados, postulava-se de forma arbitrária a solução de uma "ordem natural" única e sua "racionalidade" inquestionável, excluindo toda possibilidade de transformar minimamente a dominação hierárquica estruturalmente consolidada do trabalho pelas não analisáveis (e absolutamente inalteráveis) premissas e imperativos práticos do sistema do capital.

Assim, era inconcebível esperar algum remédio de uma concepção de dois "domínios" tão artificialmente separados, a dita sociedade civil e o idealizado "Estado ético". A estruturalmente reforçada fundação material exploradora e opressiva da sociedade - na qual o trabalho vivo foi categoricamente separado dos meios de produção e, assim, radicalmente divorciado do exercício de todas as funções societais diretivas - foi transfigurada na pretensa e mutuamente benéfica igualdade de indivíduos livremente associados por contrato (independentemente de seus conflitos pessoais egoístas, mas supostamente compatível com a harmonia societal); e toda essa construção foi envolvida 
pelas camadas reificadas de mistificação apropriadas ao funcionamento material da mais que improvável "sociedade civil", no intento de fazê-la ideologicamente aceitável. Ao mesmo tempo, os procedimentos formais/legais do Estado idealizado do ponto de vista capitalista o qual na realidade fora totalmente dominado pelo poder material do capital necessariamente pressuposto, impondo até as mais violentas forças repressivas (internamente contra sua própria força de trabalho e externamente na forma de guerras contra outros Estados), quando quer que a defesa da ordem estabelecida o exigisse - jamais poderiam contemplar qualquer mudança significativa por si mesmos. Pois as funções vitais do Estado foram historicamente articuladas como a preservação legal, política e militar (assim como assegurada nas relações de classes internas da sociedade capitalista pela grande variedade de forças policiais) das estruturas existentes de dominação e subordinação. Desse modo, tornou-se possível para a grande figura do movimento iluminista escocês, Adam Smith, idealizar o domínio do capital como o "sistema natural da liberdade e justiça completas" "xiii. E Hegel também não teve dificuldade alguma em encontrar uma caracterização, assim como uma justificação, igualmente reconciliatória e idealizante da ordem estabelecida ao postular que "se tornou objetiva a reconciliação que, em imagens e em realidade da razão, desenvolve o Estado"xiv .

Assim que as condições operativas reais da ordem sociometabólica do capital foram definidas de tal forma, por meio da conveniente separação entre a "sociedade civil" e o Estado, nenhuma solução positiva historicamente sustentável poderia ser vislumbrada como a alternativa hegemônica ao modo de reprodução estabelecido sem expor o caráter totalmente indefensável de suas determinações estruturais antagônicas. A reorientação marxiana do método foi dedicada precisamente a esse propósito.

Marx tratou com sarcasmo todos aqueles que quiseram oferecer algumas concessões limitadas e condescendentes sobre a forma prevalente da distribuição aos consumidores na ordem socioeconômica do capital enquanto mantinham seu modo de produção antagônico fetichisticamente intacto. Assim, ele escreveu que é sobremaneira absurdo quando John Stuart Mill diz: "As leis e condições da produção de riqueza assumem o caráter de verdades físicas [...] Não é assim com a distribuição de riqueza. Essa é uma questão exclusiva de instituições humanas".

As "leis e condições" da produção de riqueza e as leis de "distribuição de riqueza" são as mesmas leis sob diferentes formas, e ambas mudam, enfrentam o mesmo processo histórico; sendo assim, são apenas momentos de um processo histórico.

Não requer grandes aprofundamentos para compreender que se o ponto de partida é o trabalho livre ou assalariado, emergindo da dissolução da escravidão, as máquinas só podem surgir em antítese ao trabalho vivo, como propriedade que lhe é alheia, e como poder que lhe é hostil; ou seja, que devem confrontá-lo como capital. Mas é tão fácil quanto perceber que as máquinas não deixarão de ser agentes da produção social quando se tornarem, por exemplo, propriedade de trabalhadores associados. No primeiro caso, entretanto, sua distribuição, ou seja, o fato de que não pertencem ao trabalhador, é da mesma forma uma condição do modo de produção fundado no trabalho assalariado. No segundo caso, a mudança na distribuição terá início numa transformação na base da produção, uma nova fundação criada pela primeira vez pelo processo histórico. ${ }^{\mathrm{xv}}$

Naturalmente, a sobremaneira absurda separação e contraposição de Mill entre produção e distribuição foi concebida no interesse de eternizar a ordem de reprodução social estabelecida como um todo, ao declarar seu componente de produção como assumindo o caráter de verdades físicas. Por conseguinte, Mill não poderia oferecer nada além de pseudoconcessões vazias também sobre a própria distribuição, pois em seu esquema de coisas a distribuição tinha de permanecer encerrada nas supostas 
determinações fisicamente inalteráveis da produção enquanto tal. O completo fracasso de todas as tentativas posteriores no século XX, das tímidas reformas liberais aos ruidosamente alardeados programas socialdemocratas de transformação da sociedade (por fim abandonados de forma humilhante, de acordo com a receita do "socialismo evolucionário", o qual se supunha ser estabelecido por meio do método de "tributação progressiva", instituído no interior da estrutura do Estado de bem-estar), confirmou amplamente a validade do sarcasmo de Marx.

Ao mesmo tempo, quando oferece piedosa esperança para um modo de distribuição significativamente reformado, a dimensão mais importante do modo liberal/socialdemocrata de abordar os problemas - por meio da separação grosseira e antidialética daquilo que não pode de forma alguma ser separado na realidade efetiva significava que o intercâmbio das mediações antagônicas do metabolismo social não poderia ser alterado de modo concebível como premissa prática necessária da vida social. Mudanças poderiam ser projetadas apenas nas margens mais estreitas e nas franjas. E isso levou a descartar de forma categoricamente absoluta qualquer ideia de instituir o socialismo como a historicamente sustentável alternativa hegemônica à ordem social do capital.

A reorientação radical do método de Marx foi, ao contrário, concebida com o propósito de tornar viável aquele avanço em direção à "nova forma histórica". Essa é a razão pela qual ele frisou com muita ênfase na última de suas "Teses sobre Feuerbach", que "os filósofos apenas interpretaram o mundo de diferentes maneiras; o que importa é transformá-lo"xvi . A mudança qualitativa vislumbrada por Marx - metodologicamente vital para a crítica da economia política como anatomia dos antagonismos estruturais da sociedade civil - foi resumida por ele como o estabelecimento necessário do sistema comunal de produção e distribuição. Pois apenas por meio desse tipo de intercâmbio sociometabólico entre a humanidade e a natureza, e entre os próprios indivíduos, o círculo vicioso da mediação antagônica poderia ser rompido e substituído por um novo modo de mediação comunal não antagônica.

A esse respeito a questão central refere-se à forma específica de mediação por meio da qual a estrutura hierárquica da divisão do trabalho, sob o domínio do capital, poderia abrir caminho para o modo de reprodução diretamente social da "nova forma histórica". Em outras palavras, refere-se ao estabelecimento dos parâmetros e a direção na qual - nas palavras de Marx - "no lugar de uma divisão do trabalho",xvii (cujos imperativos materiais são impostos sem-cerimônias sobre os sujeitos do trabalho) a atividade vital conscientemente autocontrolada dos indivíduos sociais poderia ser integrada em uma totalidade produtivamente viável e humanamente realizadora.

De acordo com Marx, sob a divisão do trabalho que prevalece na sociedade mercantilizada, os indivíduos são mediados entre si mesmos e combinados de modo ineludível em uma totalidade social estruturada de forma antagônica por meio do sistema capitalista de produção e troca de mercadorias. E isso é regido pelo imperativo do valor de troca em constante expansão ao qual deve ser estritamente subordinado todo o restante das mais básicas e íntimas necessidades dos indivíduos às mais variadas atividades produtivas materiais e culturais às quais se dedicam na sociedade capitalista.

O sistema comunal vislumbrado por Marx posiciona-se em completo contraste com essa mediação societal estruturada de modo antagônico que não pode evitar impôr-se de modo brutal sobre os indivíduos por meio da relação de valor. As principais características do modo comunal de troca estão enumeradas em uma passagem seminal dos Grundrisse $e^{x v i i i}$ : 
- a determinação da atividade vital dos sujeitos trabalhadores como um vínculo necessário e individualmente significativo na produção diretamente geral e sua correspondente participação direta no mundo de produtos disponíveis;

- a determinação do próprio produto social como inerentemente comunal e geral desde o início, em relação às necessidades e propósitos comunais, baseando-se na cota especial que os indivíduos particulares adquirem na produção comunal em andamento;

- a participação plena dos membros da sociedade também no consumo comunal propriamente dito: uma circunstância que acaba por tornar-se deveras importante, em vista da inter-relação dialética entre produção e consumo, sobre cuja base esta é caracterizada

de modo adequado sob o sistema comunal como definitivo "consumo produtivo"xix;

- a organização planificada do trabalho (ao invés de sua divisão alienante, determinada pelos imperativos autoafirmativos do valor de troca na sociedade mercantilizada) de tal modo que a atividade produtiva dos sujeitos particulares do trabalho seja mediada de uma forma não reificada-objetificada, por meio da troca de mercadorias, mas por meio das condições intrinsecamente sociais do próprio modo de produção dado, no interior do qual os indivíduos são ativos.

Essas características tornam bem claro que a questão central é o estabelecimento, em termos históricos, de uma nova mediação do intercâmbio metabólico da humanidade com a natureza e da atividade produtiva autodeterminada progressivamente entre os indivíduos sociais.

A tarefa da desmistificação tinha de ser buscada de modo firme nesse âmbito. Primeiro, em relação ao conceito de troca, tratado de forma tendenciosa e com arbitrariedade unidimensional, características dos economistas políticos e filósofos que adotam o ponto de vista da sociedade civil. Citando Marx:

$\mathrm{O}$ caçador e o pescador individuais e isolados, a partir dos quais partem Smith e Ricardo, pertencem às concepções sem imaginação dos robinsonianos do século XVIII, as quais de forma alguma expressam apenas uma reação contra a sofisticação exacerbada e um retorno a uma vida natural mal compreendida, como os historiadores culturais imaginam. Também se baseia no tal naturalismo o contrato social de Rousseau, que coloca sujeitos autônomos, naturalmente independentes, em relação e conexão mediante contrato. Esta é a semelhança, aquela meramente estética, dos robinsonianos, grandes e pequenos. É, antes, a antecipação da "sociedade civil", em preparação desde o século XVI e andando a passos largos em direção à maturidade no XVIII. Nessa sociedade de competição aberta, o indivíduo aparece separado dos laços naturais etc., os quais em períodos históricos anteriores o converteram em um acessório de um conglomerado humano definido e limitado. Smith e Ricardo ainda se apoiam com os dois pés sobre os ombros dos profetas do século XVIII, em cujas imaginações esse indivíduo do século XVIII - o produto da dissolução das formas feudais da sociedade e das novas forças de produção desenvolvidas desde o século XVI - aparece como um ideal, cuja existência eles projetam sobre o passado. Não como um resultado histórico, mas sim como o ponto de partida da história. Como o Indivíduo Natural apropriado de sua noção de natureza humana, não surgindo historicamente, mas depositado pela natureza. Essa ilusão tem sido comum a cada nova época até os dias atuais. [...] Somente no século XVIII, na "sociedade civil", as várias formas de interconexão social confrontam o indivíduo como um mero meio para seus fins 
privados, como necessidade externa. Mas a época que produz esse ponto de vista, aquele do indivíduo isolado, é também precisamente aquela das relações sociais (e, sob essa perspectiva, gerais) mais desenvolvidas até esse ponto. O ser humano é no sentido mais literal um zoon politikon, não um mero animal gregário, mas um animal que pode se individuar apenas em meio à sociedade. ${ }^{\mathrm{xx}}$

No século e meio transcorrido desde o momento em que estas linhas foram escritas por Marx nada mudou substancialmente em termos metodológicos e ideológicos nas conceituações formuladas do ponto de vista da "sociedade civil" e da economia política, correspondendo ao ângulo privilegiado do capital. Ou seja, nada além de perder sua credulidade ingênua original em favor de assumir um caráter abertamente apologético e, por vezes, até cinicamente sacralizador, como no caso de Hayek e sua laia. Hoje não há mais ilusões genuínas abrigadas de modo sério em tais escritos. Porém, a projeção anistórica das relações de troca capitalistas com o passado mais remoto e a presunção arbitrária da idealizada naturalidade do sistema como um todo para propósitos ideológicos, em conjunto com a fictícia natureza humana da individualidade isolada, estão com mais evidência hoje do que em qualquer outra época.

Ademais, o fato é que nas várias concepções de "sociedade civil" o culto do indivíduo isolado é distorcido de maneira gritante. Pois sob o domínio do capital encontramos a forma social "mais desenvolvida até esse ponto"de relações de reprodução social nas quais o indivíduo efetivamente existente "pode se individuar apenas em meio à sociedade". Em outras palavras, não se pode sequer começar a pensar sobre as características definidoras elementares da individualidade capitalista sem seus vínculos orgânicos inseparáveis com a mais complexa estrutura de determinações sociais em movimento já vista na história. Esse fato desconfortável permanece como uma contradição fundamental da ordem estabelecida, e é insuperável no interior dos limites estruturais de tal ordem.

É justo por esse motivo que a distribuição deve ser separada da - e imaginariamente oposta à - produção, para criar uma credibilidade ilusória de uma ordem "natural" orientada pela (e em direção à) ótima satisfação das necessidades da individualidade isolada, quando na verdade oculta a efetividade das pressuposições práticas e dos imperativos materiais objetivos impostos pela ação bem-intencionada das personificações do capital.

Em relação ao terreno da produção enquanto tal, nem mesmo a remota aparência de um sistema coerente - capaz de surgir do caos dos intercâmbios estritamente individualistas e de adicionar milagrosamente em sua constituição um sistema socioeconômico "globalizado" totalmente não problemático - poderia ser plausível sequer por um momento. Tão só a metodologia "sobremaneira absurda" de abstrair a distribuição de sua necessária base de produção (incuravelmente nociva), pode gerar o mito de uma sociedade equitativa enquanto preserva absolutamente intactas suas determinações discriminatórias estruturalmente reforçadas. Além disso, a dimensão mais significativa da distribuição mesma, quando considerada em sua integralidade dialética - o tabu absoluto a respeito da distribuição primária de meios e materiais de produção à propriedade exclusivista das personificações do capital -, é removida (caberia dizer com mais propriedade: contrabandeada) da "sobremaneira absurda" preocupação condescendente com a "distribuição" desconjuntada de produtos aos consumidores, como parte e parcela das mistificações convenientemente derivadas do "ponto de vista da sociedade civil".

Entretanto, não obstante toda a mistificação metodológica e ideológica, a contradição subjacente fundamental não pode ser removida do sistema. Pelo contrário, cada vez mais se aprofunda e se intensifica, e mais cedo ou mais tarde deverá ser 
contemplada na própria realidade. Pois não estamos falando de um traço periférico ou marginal, mas sim de uma contradição central do sistema do capital em sua totalidade: aquele entre a tendência em direção à socialização crescente e integração global da produção e a intocável apropriação privada do produto societal total, incluindo, obviamente, os meios de produção potencialmente mais poderosos de toda a sociedade inventados pela ciência e expropriados de modo unilateral em subordinação às necessidades e determinações autoexpansivas do capital.

Ninguém poderia (ou, talvez, nem mesmo desejaria) negar que, hoje, a "globalização" - independente do quão em voga seja tratá-la como regra - pertence às "relações sociais (e, sob essa perspectiva, gerais) mais desenvolvidas até esse ponto", nas palavras de Marx, embora os ideólogos do capital sejam sem dúvida propensos a negar seu caráter contraditório. Não obstante, o problema grave é que a tendência realmente existente de globalização não pode ser levada a uma completude histórica sustentável por causa da contradição fundamental entre o crescimento significativo da socialização da produção e a cada vez mais exclusivista em sua definitiva tendência monopolistica/imperialisticamente destrutiva apropriação/expropriação de todas as suas dimensões, incluindo sua base produtiva.

Tampouco devemos ser crédulos o suficiente para aceitar a afirmação propagandística e serviente a si mesma de que a "globalização" é um tipo radicalmente novo de desenvolvimento cujo resultado seria: vivermos felizes para sempre em todo o mundo. Na realidade ela é inseparável de uma categoria vital do desenvolvimento global do sistema, e neste sentido é tão antiga quanto o próprio capital industrial. Ou seja, a tendência inexorável em direção à concentração e centralização do capital $^{x x i}$. De fato, o progresso dos desenvolvimentos monopolísticos em geral não é de modo algum inteligível sem essa categoria. Ademais, até o tipo monopolístico de desenvolvimento não é tão novo quanto frequentemente se presume. Pois Marx havia posto em relevo já em 1857, em seus Grundrisse:

Como um outro exemplo das posições divergentes que pode ocupar a mesma categoria em diferentes estágios sociais: uma das formas mais recentes da sociedade burguesa, sociedades anônimas por ações. Estas também aparecem, no entanto, em sua origem, nas grandes e privilegiadas empresas de monopólio. ${ }^{\text {xii }}$

Assim, por exemplo, a monopolisticamente privilegiada e militarmente protegida Companhia das Índias Orientais, em um passado até certo ponto remoto, foi uma óbvia precursora do imperialismo colonial. As duas guerras mundiais do século XX são uma lembrança inegável da suposta natureza "benéfica em todos os aspectos" de tais desenvolvimentos. Tampouco podemos dar-nos ao luxo de fantasiar sobre a tendência da globalização em andamento se abstraímos suas profundas interconexões com as mais cruéis formas de dominação imperialista, incluindo a determinação de seus esmagadores poderes dominantes para precipitar até mesmo guerras genocidas, caso e quando quer que lhe sirva, no modelo do passado imperialista.

A reorientação marxiana do método é importante de modo vital em todos esses aspectos, pois as graves e globalmente intensificadas contradições de nossa ordem social não podem ser deixadas permanentemente sob o manto da mistificação metodológica e ideológica. A contradição irreconciliável entre socialização e apropriação da produção identificada ao sublinhar-se que "a época que produz o ponto de vista do indivíduo isolado é também precisamente aquela das relações sociais (e, sob essa perspectiva, geral) mais desenvolvidas até esse ponto, em que o indivíduo só pode se individuar em meio à sociedade" - deve ser resolvida numa forma histórica sustentável. Ou seja: trazendo o metabolismo social em sua totalidade, incluindo a satisfação das necessidades genuínas dos indivíduos, em plena sintonia com a necessária socialização 
da produção, e isso sendo feito de tal modo que possa ser controlado de maneira apropriada pelos próprios indivíduos sociais livremente associados.

A única maneira concebível de cumprir de forma bem-sucedida essa tarefa histórica é por meio da instituição e consolidação do verdadeiro sistema comunal de produção e consumo, em sua inseparabilidade dialética recíproca, como sempre fora defendido por Marx. Nesse âmbito, não pode haver "ponto intermediário", como evidenciado claramente pelo total fracasso de todas as tentativas reformistas que no passado foram concebidas do ponto de vista e no espírito de uma "sociedade civil" historicamente insustentável.

Uma das questões metodológicas mais importantes a esse respeito refere-se à distorção tendenciosa e à projeção mistificadora das relações de troca capitalistas em direção ao passado remoto.

Sem dúvida, nenhuma forma social em qualquer nível de complexidade é concebível sem alguma forma de relação de troca. De fato, o termo "social" é em certo sentido sinônimo disso. A "única" questão é que a troca precisa ser entendida como inseparável, de modo genuíno, da própria vida social. É isso que, em última instância, decide a questão quando nos referimos à necessária sustentabilidade histórica da alternativa hegemônica à ordem sociometabólica do capital.

Contudo, o grave problema é que as relações de troca sob o domínio do capital estão sujeitas à tirania da lei do valor. As consequências inevitáveis disso são alienantes e rigidamente constrangedoras para os seres humanos - como a dominação até das mais fundamentais necessidades de incontáveis milhões, dependentes dos valores de uso para a satisfação de suas necessidades, e a necessidade capitalista imposta em insensível subordinação à produção de valores de troca que geram lucros.

$\mathrm{Na}$ atualidade, o significado central do termo "troca" refere-se ao inevitável intercâmbio metabólico com a natureza por parte da humanidade, por um lado, e às relações de intercâmbio dos indivíduos particulares entre eles mesmos, por outro. Independente do que possam vir a ser as formas históricas específicas, esse é o caso exigido para realizar os objetivos vislumbrados da reprodução social da humanidade.

Nesse sentido fundamental, o significado da categoria de intercâmbio é inseparável da mediação historicamente necessária, indicando de modo claro o caráter processual daquilo que realmente está em jogo. Em franco contraste, sob a tirania da lei do valor, somos confrontados com as determinações fetichistas/reificantes da troca de mercadorias. Pois, no interior da estrutura do sistema do capital, a única forma possível de legitimar valores de uso correspondentes às necessidades humanas é produzir mercadorias que assegurem os lucros, sob o imperativo da acumulação de capital sempre expansiva.

Isso é extremamente problemático porque, na realidade, a satisfação das necessidades humanas está vinculada à provisão de bens ou produtos, seja como objetos ou serviços, e não de mercadorias. Entretanto, sob o domínio do capital, o significado de "produtos" é brutalmente distorcido, pois eles podem ser legitimados no âmbito da produção e distribuição do sistema do capital apenas enquanto produtos mercantilizados, sejam objetos ou serviços. E, pior ainda, até mesmo o exercício da força de trabalho - e, com ele, a sobrevivência do próprio trabalho vivo sob o domínio do capital - pode adquirir legitimidade para sua reprodução (ou seja, sua sobrevivência contínua) apenas sob a condição de que seja convertido em mercadoria.

Observando as condições para a reprodução em seu sentido fundamental, como intercâmbio metabólico da humanidade com a natureza e dos indivíduos particulares entre si, o papel atribuído aos produtos requer reflexão crítica, sem mencionar a mercantilização dos produtos que deve ser rejeitada como uma desumanização ultrajante. Pois, mesmo em relação aos produtos, a questão permanece ineludível: o quão 
justificáveis são os propósitos para os quais são produzidos quando considerado o ponto de vista da satisfação humana genuína dos indivíduos livremente associados, e não em sintonia com as determinações alienantes das relações de troca capitalistas que necessariamente as convertem em mercadorias, inventando e impondo sobre a sociedade até as mais artificiais "necessidades" (na verdade, apetites artificiais) quando as condições de lucratividade o exigem.

Nesse sentido, o papel reservado aos produtos pode constituir apenas uma etapa subordinada nesse complexo de problemas. A primazia pertence ao lado ativo/produtivo, mesmo se esse fato é seriamente distorcido pela modalidade capitalista da objetivação que assume de modo necessário a forma de alienação e reificação fetichista. Ainda assim, a verdade nua e crua é que também a mercadoria capitalista deve ser primeiro produzida, por meio do intercâmbio e da troca de uma grande multiplicidade de atividades, antes que possa entrar no mercado na busca direta de lucro.

É aqui que podemos ver a grande importância da defesa, por Marx, do sistema comunal de produção e consumo como a única solução viável às mediações antagônicas do capital e como a alternativa hegemônica viável à ordem estabelecida. Em gritante contraste com a produção de mercadorias e suas relações de troca reificadas, o caráter histórico inovador do sistema comunal define-se por meio de sua orientação prática em direção à troca de atividades, e não apenas de $\operatorname{produtos}^{\text {xxiii }}$. Naturalmente, a alocação de produtos emerge da própria atividade produtiva organizada de forma comunal. Mas o ponto é que, no sistema comunal, a primazia necessariamente pertence à autodeterminação e à correspondente organização das atividades mesmas na qual os indivíduos livremente associados se envolvem em concordância com sua necessidade enquanto seres humanos ativos e criativos. Em outras palavras, sob o sistema comunal, a produção ocuparia de maneira consciente o lugar em resposta à necessidade, sobretudo, à necessidade básica dos indivíduos da atividade vital humanamente realizadora. Pois esta é uma questão inerentemente qualitativa, e somente os próprios indivíduos podem ser seus juízes, em contraposição à idealizada "mão invisível", que é apenas um nome mais respeitável para a tirania da lei do valor do capital.

A transição radical das relações de troca estabelecidas orientadas para a produção e distribuição de produtos mercantilizados - ou nem mesmo plenamente mercantilizados, como no sistema de tipo soviético - a um modo qualitativamente diverso, baseado na troca de atividades, é o único caminho viável para substituir a modalidade antagônica, definitivamente destrutiva, de mediação do intercâmbio metabólico da humanidade com a natureza e dos indivíduos entre si, por uma alternativa socialmente harmônica e historicamente sustentável. Pois se as atividades são predeterminadas por objetivos prévios de produção, sejam eles estabelecidos pelos imperativos da produção de mercadorias ou por uma autoridade política separada, em vez dos objetivos mesmos serem estabelecidos sobre a base das determinações conscientes dos indivíduos que se ocupam das várias atividades produtivas, nesse caso não pode haver nenhuma garantia contra antagonismos que surjam em torno da distribuição dos produtos ou acerca do modo pelo qual as atividades são designadas aos indivíduos produtores em subordinação às metas de produção preestabelecidas. É por esse motivo que não pode haver "ponto intermediário" entre a modalidade antagônica de reprodução social e o sistema comunal.

Outra razão vital para o estabelecimento do sistema comunal defendido por Marx é a irreversível natureza perdulária de todos os sistemas de produção e distribuição possíveis que não sejam orientados pela atividade vital conscientemente escolhida dos indivíduos associados. Ou seja, os indivíduos que intercambiam livremente suas atividades entre eles 
mesmos, baseados não na divisão hierárquica, mas na organização substantivamente equitativa do trabalho, em concordância com um plano abrangente estabelecido pelos e para os próprios indivíduos.

Geralmente se aceita que, por meio do desenvolvimento das forças produtivas da sociedade, incluindo o grande avanço da ciência, abre-se a possibilidade de se superar a escassez para a humanidade. Mas a produção da abundância, há muito prevista, está condenada a permanecer como uma potencialidade abstrata sem um modo adequado de produção e distribuição, que seria viável apenas sob o sistema comunal. Tornar tal potencialidade abstrata em efetividade criativa exige a reorientação do processo de reprodução social como um todo, de tal forma que os bens e serviços produzidos de maneira comunal possam ser plenamente compartilhados, e não individualisticamente desperdiçados, por todos aqueles que participam da produção e do consumo imediatamente sociais, porque eles optam e controlam por definitivo sua própria atividade. Se prescindirem desse tipo de autorregulação consciente, até mesmo os recursos da mais rica sociedade possível permanecerão aprisionados no interior do círculo vicioso da escassez autorrenovadora e imponente até em termos dos apetites descontrolados de grupos relativamente limitados de pessoas, e muito mais, em consequência, em relação à totalidade de indivíduos.

Dois comentários finais fazem-se necessários a esta altura. Primeiro, que no campo da economia e da filosofia políticas a determinação social do método na época do capital corre em direção totalmente contrária a tudo isso ao eternizar as relações de troca do sistema do capital, historicamente estabelecidas e necessariamente transitórias em termos de época, assim como pelo preocupante culto do indivíduo isolado em consonância com esses elementos. A conclusão é que o engajamento constante no trabalho da desmistificação crítica permanece como um desafio para nós.

O segundo comentário a ser feito é que a reorientação marxiana do método põe em relevo a inseparabilidade dos aspectos metodológicos dos problemas encontrados em sua dimensão substantiva. Contrariando a frequente separação especulativa e formalista do método em relação aos aspectos complexos e contradições da vida social na teoria costumeiramente justificada sob o argumento de que a clarificação de pontos metodológicos complicados envolve a investigação das facetas mais mediadas do discurso filosófico -, as questões de método não estão menos envolvidas com os problemas substantivos da vida social. Com frequência o caso é o oposto, e as grandes dificuldades e complicações metodológicas surgem precisamente da extrema complexidade e contraditoriedade das questões socioeconômicas em jogo, exigindo uma abordagem radical crítica das próprias questões substantivas a fim de torná-las capazes de capturar sua dimensão metodológica. A reorientação marxiana do método vista nesta seção é um exemplo ilustrativo de como trazer à vida de modo pleno até mesmo os problemas mais complexos e abstratos de modo proibitivo no discurso filosófico tradicional, e elucidando-os a partir da interdependência de suas dimensões fundamentais.

\section{Referências}

Hegel, G.W.F. Princípios da filosofia do direito. São Paulo: Martins Fontes, 2003. 
Marx, Karl. O capital: crítica da economia política. Rio de Janeiro: Civilização Brasileira, 2002. V. 2, livro primeiro, parte 7, cap. XXIV, seção 7.

. Contribuição à crítica da economia política. São Paulo: Martins Fontes, 1983 Penguin, 1973.

Grundrisse: Foundations of the Critique of Political Economy. Londres:

Marx, Karl; Engels, Friedrich. A ideologia alemã. São Paulo: Boitempo, 2007

Mészáros, Itsvan. A teoria da alienação em Marx. São Paulo: Boitempo, 2006.

Boitempo, 2002.

Para além do capital: rumo a uma teoria da transição. São Paulo:

Smith, Adam, A riqueza das nações. São Paulo: Nova Cultural, 1996

${ }^{\text {i }}$ Filósofo. Professor Emérito de Filosofia na Universidade de Sussex, Inglaterra

ii Karl Marx, "Prefácio", em Contribuição à crítica da economia política (trad. Maria Helena Barreiro Alves, 2. ed., São Paulo, Martins Fontes, 1983), p. 25.

iii Marx fala a respeito de "um pressuposto prático, absolutamente necessário, pois sem ele apenas se generaliza a escassez e, portanto, com a carestia, as lutas pelos gêneros necessários recomeçariam e toda a velha imundice acabaria por se restabelecer", Karl Marx e Friedrich Engels, A ideologia alemã (trad. Rubens Enderle, Nélio Schneider e Luciano Cavini Martorano, São Paulo, Boitempo, 2007), p. 38, nota c.

${ }^{\text {iv }}$ Karl Marx, Contribuição à crítica da economia política, cit., p. 25.

${ }^{v}$ Karl Marx e Friedrich Engels, A ideologia alemã, cit., p. 537-8.

${ }^{\text {vi }}$ Ibidem, p. 41-2.

vii Ibidem, p. 41.

viii Ibidem, p. 73.

ix Ver meu livro A teoria da alienação em Marx (São Paulo, Boitempo, 2006).

x Para uma discussão mais detalhada desses problemas ver o capítulo 4 de meu livro Para além do capital: rumo a uma teoria da transição (São Paulo, Boitempo, 2002).

${ }^{x i}$ Karl Marx, Contribuição à crítica da economia política, cit., p. 24.

xii Ibidem, p. 25.

xiii Adam Smith, A riqueza das nações (trad. Luiz João Baraúna, 19. ed., São Paulo, Nova Cultural, 1996, Coleção Os Pensadores, vol. II), p. 100.

${ }^{\text {xiv }}$ G.W.F. Hegel, Princípios da filosofia do direito (trad. Orlando Vitorino, São Paulo, Martins Fontes, 2003), p. 317. Há até um toque de cinismo com relação às efetivas funções destrutivas do "Estado ético", incluindo a idealização de suas guerras, quando - desdenhando da otimista projeção de Kant de "paz eterna" - ele conclui que "a estagnação em que os mergulharia numa indefinida tranquilidade, assim uma paz eterna faria estagnar os povos", ibidem, p. 298.

${ }^{x v}$ Karl Marx, Grundrisse: Foundations of the Critique of Political Economy (trad. Martin Nicolaus, Londres, Penguin, 1973), p. 832-3.

${ }^{\text {xvi }}$ Cf. a $11^{\underline{a}}$ e conclusiva tese de Marx sobre Feuerbach em Karl Marx e Friedrich Engels, A ideologia alemã, cit., p. 535.

${ }^{\text {xvii }}$ Karl Marx, Grundrisse, cit., p. 172. 
xviii Ibidem, p. 171-2

xix Aqui podemos ver a relevância da dura crítica de Marx à oposição não dialética entre produção e distribuição formulada por John Stuart Mill.

${ }^{\mathrm{xx}}$ Karl Marx, Grundisse, cit., p. 83-4.

xxi Marx descreve o processo de centralização do capital como a expropriação de muitos por poucos capitalistas, sublinhando ao mesmo tempo as implicações de longo alcance desse processo para a socialização da produção em uma escala global. Assim é colocado pelo próprio: "Essa expropriação se opera pela ação das leis imanentes à própria produção capitalista, pela centralização dos capitais. Cada capitalista elimina muitos outros capitalistas. Ao lado dessa centralização ou da expropriação de muitos capitalistas por poucos, desenvolve-se, cada vez mais, a forma cooperativa do processo de trabalho, a aplicação consciente da ciência ao progresso tecnológico, a exploração planejada do solo, a transformação dos meios de trabalho em meios que só podem ser utilizados em comum, o emprego econômico de todos os meios de produção manejados pelo trabalho combinado, social, o envolvimento de todos os povos na rede do mercado mundial e, com isso, o caráter internacional do regime capitalista", Karl Marx, O capital: crítica da economia política (trad. Reginaldo Sant'Anna, 18. ed., Rio de Janeiro, Civilização Brasileira, 2002, v. 2, livro primeiro, parte 7, cap. XXIV, seção 7), p. 875.

xxii Idem, Grundrisse, cit., p. 108.

xxiii Ibidem, p. 171. Como exposto por Marx: "Desde o início, o caráter comunal da produção converteria o produto em produto comunal, geral. A troca que originalmente ocorre na produção - que não seria uma troca de valores de troca, mas de atividades, determinadas por necessidades e propósitos comunais - incluiria desde o começo a participação dos indivíduos no mundo comunal dos produtos".

Recebido dia 10/03/2010

Avaliado dia 20/05/2010 